\title{
Dampak Implementasi Insentif dan Jaminan Sosial Membantu Meningkatksan Produktivitas Kerja Karyawan Pada UD Kembang Batu Lestari di Mengwi Badung
}

\author{
Ni Putu Sri Mariyatni* dan I Made Setena \\ Fakultas Ekonomi dan Bisnis Universitas Warmadewa, Denpasar, Bali-Indonesia \\ srimariyatni17@gmail.com
}

\begin{abstract}
How to cite (in APA style):
Mariyatni, N. P. S., \& Setena, I. M. (2021). Dampak Implementasi Insentif dan Jaminan Sosial Membantu Meningkatksan Produktivitas Kerja Karyawan Pada UD Kembang Batu Lestari di Mengwi Badung. Wacana Ekonomi (Jurnal Ekonomi, Bisnis dan Akuntansi), 20 (2), pp.110-117. https://doi.org/10.22225/we.20.2.2021.110-117
\end{abstract}

\begin{abstract}
This study aims to determine the impact of the implementation of incentives and social security programs to help increase employee productivity. This research was conducted at UD Kembang Batu Lestari in Mengwi Badung. The population in this study were 35 employees of UD Kembang Batu Lestari, the method of determining the sample using the census method that all employees became respondents. The analysis technique used is multiple linear regression analysis. The results of multiple linear regression analysis $Y=$ $0.603+0.400 X 1+0.515 X 2$. This means that the increase in employee work productivity is influenced by the increase in incentives and social security together. The F-test is a test of the significance of multiple linear regression coefficients obtained by F-count 83.262> F-table 3.23, indicating that there is indeed a significant effect simultaneously. between incentives and guarantees of employee work productivity. The significance test using the t-test obtained the t-value for the incentive and social security variables, respectively 2.747 and 4.157> t-table 1.684, indicating that it is true that there is a positive and partially significant effect between incentives and social security on work productivity employees.
\end{abstract}

Keywords: Incentives; Social Security; Work Productivity.

\begin{abstract}
Abstrak
Penelitian ini bertujuan untuk mengetahui dampak implementasi insentif dan program jaminan sosial membantu meningkatkan produktivitas kerja karyawan. Penelitian ini dilakukan pada UD Kembang Batu Lestari Di Mengwi Badung. Populasi dalam penelitian ini adalah karyawan UD Kembang Batu Lestari berjumlah 35 orang, metode penentuan sampel menggunakan metode sensus yaitu seluruh karyawan dijadikan responden. Teknik analisisyang digunakan yaitu analisa regresi linier berganda. Hasil analisis regresi linier berganda $\mathrm{Y}=0,603+0,400 \mathrm{X} 1+0,515 \mathrm{X} 2$. Artinya meningkatnya produktivitas kerja karyawan dipengaruhi oleh meningkatnya insentif dan jaminan sosial secara bersama-sama.Pengujian F-test adalah uji signifikansi koefisien regresi linier berganda diperoleh F-hitung 83,262 > F-tabel 3,23, menunjukkan memang benar ada pengaruh yang signifikan secara simultan antara insentif dan jaminan terhadap produktivitas kerja karyawan. Uji signifikansi dengan menggunakan t-test diperoleh nilai t-hitung untuk variabel insentif dan jaminan sosial masing-masing sebesar 2,747 dan 4,157>t-tabel 1,684, menunjukkan memang benar ada pengaruh yang positif dan signifikan secara parsial antara insentif dan jaminan sosial terhadap produktivitas kerja karyawan.
\end{abstract}

Kata Kunci: Insentif; Jaminan Sosial; Produktivitas Kerja.

\section{PENDAHULUAN}

Sumber daya manusia yang terampil merupakan salah satu faktor produksi yang terpenting dalam perusahaan. Dalam melaksanakan tugas yang dibebankan, manusia memerlukan motivasi yang dapat mendorong dirinya untuk meningkatkan produktivitas kerja. Produktivitas kerja adalah kemampuan dalam memanfaatkan sarana dan prasarana yang telah disediakan oleh perusahaan sehingga dapat menghasilkan output yang optimal (Simamora, 2006). Salah satu faktor yang dapat mempengaruhi produktivitas kerja karyawan adalah insentif. Insentif merupakan salah satu cara yang efektif diterapkan di setiap perusahaan. Insentif adalah tambahan bonus yang bertujuan untuk meningkatkan produktivitas karyawan dan untuk mempertahankan karyawan yang berprestasi agar tetap berada dalam perusahaan (Martoyo, 2007).

Research gap dalam penelitian ini yaitu masih diketahui adanya inkonsistensi hasil penilitian terdahulu, seperti penelitian yang dilakukan oleh Khafidoh (2015) menunjukkan hasil bahwa insentif 
berpengaruh positip signifikan terhadap produktivitas kerja karyawan. Hasil penelitian yang sama juga dilakukan oleh (Subagyo, 2017) yang menyatakan bahwa insentif berpengaruh signifikan terhadap produktivitas kerja karyawan. Tetapi tidak sejalan dengan penelitian yang dilakukan oleh (Kim, Kim \& Kim, 2017) bahwa insentif tidak berpengaruh terhadap produktivitas karyawan. Selain insentif, faktor lain yang dapat mempengaruhi produktivitas kerja karyawan adalah jaminan sosial. Jaminan sosial merupakan jaminan terhadapkemungkinan hilangnya pendapatan bunga sebagian atau seluruhnya, bertambahnya pengeluaran karena sakit, kecelakaan, hari tua, meningal dunia atau resiko sosial lainnya" (Khafidoh, 2015).

Research Gap, Penelitian (Supriadi, 2017) yang menjelaskan hubungan antara jaminan sosial dan produktivitas memiliki hubungan yang berpengaruh signifikan. Namun menurut (Lukitasari, 2015) hubungan antara jaminan sosial dengan produktivitas adalah sangat rendah dan negatif. Penelitian oleh (Jessica, 2016), bahwa terdapat pengaruh yang positip dan signifikan antara Insentif Dan Jaminan Sosial secara simultan maupun parsial Terhadap Produktivitas Kerja Karyawan.UD. Kembang Batu Lestari merupakan salah satu perusahaan yang bergerak di bidang industri manufaktur yang melayani pembuatan pelinggih/sanggah, bale Bali, pintu gebyog dan aneka produk stil Bali lainnya. UD. Kembang Batu Lestari ini telah berdiri sejak tahun 2011, berlokasi di Jalan Raya Tangeb, Abianbase, Kecamatan Mengwi, Kabupaten Badung. UD. Kembang Batu Lestari mempekerjakan sebanyak 35 orang karyawan. Untuk mengetahui tingkat produktivitas kerja karyawan dapat dilihat dari target dan realisasi yang dicapai. UD. Kembang Batu Lestari menetapkan target penjualan selama tahun 2019 rata-rata Rp. 150.000.000/bulan, namun realisasi rata-rata hanya 91\%/bulan, hal ini menunjukkan rendahnya produktivitas kerja karyawan Dalam upaya meningkatkan kinerja karyawan, UD. Kembang Batu Lestari memiliki beberapa kebijakan. Kebijakan pertama adalah dengan pemberian insentif yang berupa bonus. Bonus diberikan pada karyawan yang bekerja sesuai dengan standar, prestasi kerja, ketepatan waktu, dan sikap karyawan. Selain insetif, untuk memelihara dan menekan tingkat labour turn over karyawan, perusahaan menerapkan program jaminan sosial. Bentuk jaminan sosial yang diberikan seperti jaminan hari tua, kecelakaan kerja dan pemeliharaan kesehatan. Hasil wawancara awal dengan beberapa orang karyawan, menunjukkan adanya indikasi beberapa keluhan karyawan waktu kerja melebihi waktu standar, target terlalu tunggi, jaminan sosial diberikan dalam bentuk balas jasa sesuai sesuai kontribusi karyawan di tempat kerja, belum mengikuti ketentuan pemerintah. Fenomena ini perlu mendapat perhatian yang lebih serius agar dapat merangsang semangat, loyalitas karyawan dan produktivitas kerja akan lebih baik.

Berdasarkan latar belakang masalah yang diuraikan diatas, dapat dirumuskan permasalahan sebagai berikut: Sejauh mana dampak implementasi program insentif dan jaminan sosial membantu meningkatkan produktivitas kerja karyawan pada UD Kembang Batu Lestari Di Mengwi Badung?. Tujuan Penelitian untuk menguji secara empiris sejauh mana dampak implementasi program insentif dan jaminan sosial membantu meningkatkan produktivitas kerja karyawan pada UD kembang Batu Lestari Di Mengwi Badung.

\section{TINJAUAN PUSTAKA}

\section{Produktivitas}

Produktivitas adalah hubungan antara output atau jumlah barang yang diproduksi dalam suatu periode tertentu dengan faktor produksi (material, tenaga kerja dan modal atau dana) yang digunakan untuk menghasilkan produk (Sudiro, 2011).

\section{Pengukuran Produktivitas}

Faktor-faktor yang digunakan dalam pengukuran produktivitas kerja adalah: 1) Kualitas kerja , 2) Kuantitas kerja dapat diartikan sebagai hasil yang telah dicapai oleh karyawan dalam jumlah tertentu dengan perbandingan standar yang ada. 3) Ketepatan waktu dapat diartikan sebagai suatu tingkatan dari aktivitas yang telah diselesaikan pada awal waktu ditetapkan, dapat diukur dari persepsi karyawan terhadap suatu aktivitas yang diselesaikan diawal waktu sampai menjadi output (Simamora, 2006).

Faktor-faktor yang Mempengaruhi Produktivitas 
Faktor yang mempengaruhi produktivitas karyawan: 1) Kualitas dan kemampuan fisik karyawan. 2) Sarana pendukung, yang menyangkut lingkungan kerja, teknologi dan cara produksi, sarana dan peralatan produksi, tingkat keselamatan dan kesehatan kerja. 3) Supra sarana, aktivitas perusahaan (Afrida, 2003).

Indikator Produktivitas Kerja

Indikator produktivitas kerja meliputi : 1). Kuantitas Kerja, Jumlah produk yang dapat dicapai oleh karyawan dengan standar yang ditetapkan perusahaan. 2). Kualitas Kerja, Kemampuan karyawan dalam menyelesaikan pekerjaannya meliputi kesesuaian, kelengkapan, dan kerapian produk dengan standar yang telah ditetapkan perusahaan. 3). Ketepatan Waktu, Ketepatan waktu diukur berdasarkan presepsi karyawan terhadap suatu aktivitas yang disediakan diawal sampai menjadi outoput (Simamora, 2006).

\section{Insentif}

Insentif adalah suatu sarana memotivasi berupa materi, yang diberikan sebagai suatu perangsang ataupun pendorong dengan sengaja kepada para pekerja agar dalam diri mereka timbul semangat yang besar untuk meningkatkan produktivitas kerjanya dalam organisasi (Gorda, 2004).

\section{Tujuan Pemberian Insentif}

Fungsi utama dari insentif adalah untuk memberikan tanggung jawab dan dorongan kepada karyawan. Insentif menjamin bahwa karyawan akan mengarahkan usahanya untuk memcapai tujuan organisasi. Sedangkan tujuan utama pemberian insentif adalah untuk meningkatkan produktivitas kerja individu maupun kelompok (Panggabean, 2002).

Indikator Insentif

1) Insentif Material, yaitu insentif dalam bentuk uang seperti: Bonus, Komisi, Profit share, Kompensasi, 2) Insentif non material yaitu insentif tidak dalam bentuk uang, seperti: Pemberian gelar (title) secara resmi, Pemberian tanda jasa atau medali, Pemberian piagam penghargaan, Pemberian pujian lisan maupun tulisan secara resmi ataupun secara pribadi, Ucapan terima kasih secara formal atau informal, Pemberian hukum untuk menggunakan suatu atribut jabatan (Sarwoto, 2010).

\section{Jaminan Sosial}

Dalam Undang-Undang No. 3 pasal 1 ayat 1 Tahun 1992 tentang jaminan sosial tenaga kerja, Jaminan sosial tenaga kerja adalah suatu perlindungan bagi tenaga kerja dalam bentuk satuan berupa uang sebagai pengganti sebagian dari penghasilan yang hilang atau berkurang dalam pelayanan sebagai akibat peristiwa yang dialami oleh tenaga kerja berupa kecelakaan kerja, sakit, bersalin, hari tua, dan meninggal dunia.

\section{Tujuan Jaminan Sosial Nasional}

1) Memberikan jaminan terpenuhinya kebutuhan dasar hidup layak bagi setiap peserta dan anggota keluarganya. 2) Memberi kepastian perlindungan, bila terjadi hal-hal yg mengakibatkan hilang atau berkurangnya pendapatan karena sakit, kecelakaan, kehilangan pekerjaan, memasuki usia lanjut/pensiun (UU No 40 Tahun 2004 tentang SJSN).

\section{Manfaat Jaminan Sosial Nasional}

1) Mewujudkan hubungan industrial harmonis, 2) Mendukung ketenangan bekerja dan keberlangsungan usaha, 3) Pemenuhan hak dasar pekerja dan hak asasi manusia, 4) Mendukung motivasi dan produktivitas kerja, 5) Hidup layak dan sejahtera saat bekerja dan pasca bekerja (UU No 40 Tahun 2004 tentang SJSN).

\section{Indikator Jaminan Sosial}

1) Memberikan perlindungan dasar untuk memenuhi kebutuhan hidup minimal bagi tenaga kerja serta keluarganya, 2) Dengan adanya upaya perlindungan dasar akan memberikan kepastian berlangsungnya arus penerimaan penghasilan, sebagai pengganti atau seluruh penghasilan yang hilang, 3) Menciptakan ketenangan kerja karena adanya upaya perlindungan terhadap resiko ekonomi maupun sosial (Kansil, 2007).

\section{Hasil Penelitian Terdahulu}


Sebagai pembanding dalam penelitian ini, peneliti menggunakan beberapa penelitian sebelumnya.

Penelitian pertama dilakukan oleh (Jessica, 2016) dengan judul Pengaruh Insentif Dan Jaminan Sosial Terhadap Produktivitas Kerja (Studi pada Karyawan AJB Bumiputera 1912 Kantor Wilayah Malang). Hasil penelitian menunjukkan bahwa terdapat pengaruh yang positip dan signifikan antara Pemberian Insentif Dan Program Jaminan Sosial secara simultan maupun parsial Terhadap Produktivitas Kerja Karyawan.Penelitian kedua dilakukan oleh (Siregar, 2020) dengan judul Pengaruh Insentif Dan Jaminan Sosial Terhadap Produktivitas Karyawan Pada PT. Muamalat Indonesia Tbk. Hasil penelitian menunjukkan bahwa terdapat pengaruh yang positip dan signifikan antara Insentif Dan Jaminan Sosial secara simultan maupun parsial Terhadap Produktivitas Kerja Karyawan.

\section{Kerangka Pemikiran}

Kerangka pemikiran dinyatakan dalam bentuk skema sederhana tetapi utuh memuat pokokpokok unsur penelitian dan tata hubungan antara pokok-pokok unsur penelitian, seperti pada gambar berikut :

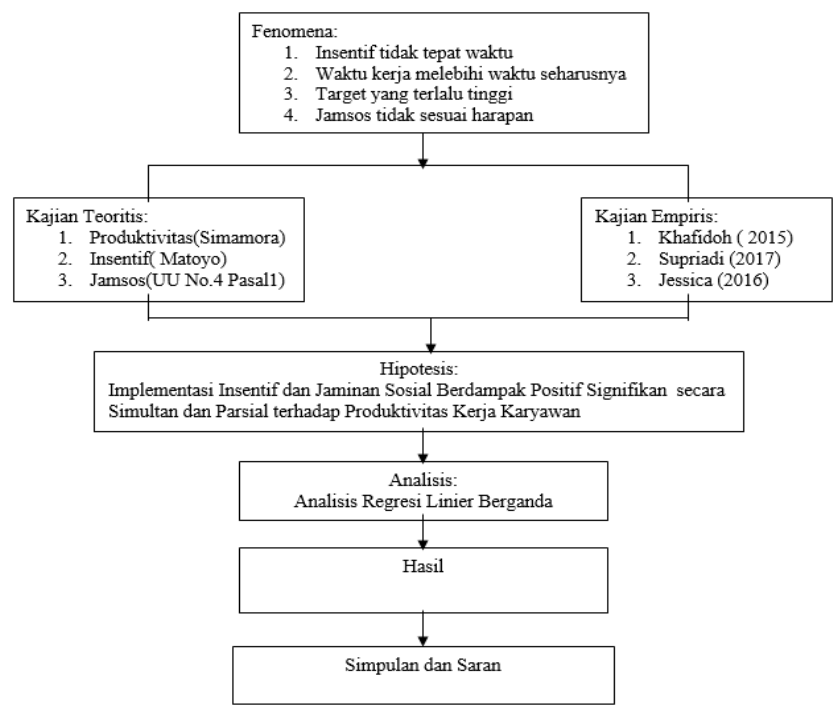

Gambar 1

Kerangka Pemikiran

\section{Kerangka Konsep}

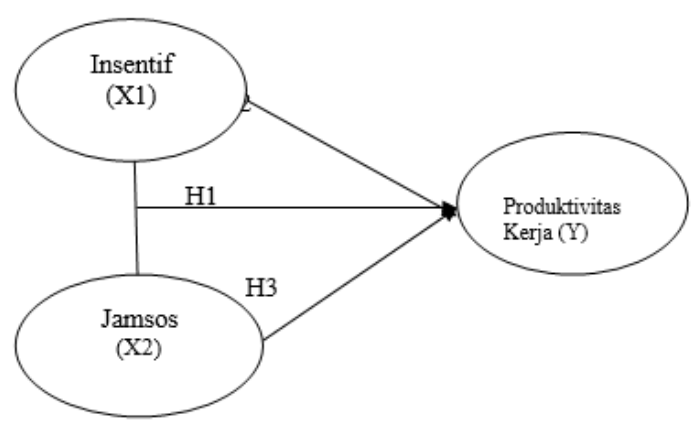

Gambar 2

Kerangka Konsep

\section{Hipotesis Penelitian}

Berdasarkan landasan teoritis, publikasi penelitian sebelumnya dan kerangka pemikiran, dapat dinyatakan hipotesis sebagai berikut :

Implementasi progran insentif dan jaminan sosial berdampak positip dan signifikan membatu 


\section{METODE}

Lokasi penelitian dilakukan pada UD. Kembang Batu Lestari, yang bergerak di bidang industri manufaktur yang melayani pembuatan pelinggih/sanggah, bale Bali, pintu gebyog dan aneka produk stil Bali lainnya, yang beralamat di Jalan Raya Tangeb, Abianbase, Kecamatan Mengwi, Kabupaten Badung. Peneliti memilih lokasi ini karena tertarik untuk mengkaji sejauh mana implementasi insentif dan jaminan sosial membantu meningkatkan produktivitas kerja karyawan pada UD. Kembang Batu Lestari di Mengwi Badung.

\section{Populasi dan Sampel}

Populasi dalam penelitian ini adalah seluruh karyawan UD Kembang Batu Lestari berjumlah 35 orang. Dalam penelitian ini sampel dikumpulkan menggunakan metode sensus, dimana seluruh karyawan dijadikan responden penelitian.Teknik sampel jenuh atau sensus digunakan bila populasi kurang dari 100 orang (Sugiyono, 2017).

\section{Definisi Operasional Variabel}

Untuk mendefinisikan suatu variabel yang terkait dengan obyek penelitian, maka dibuat beberapa pengertian batasan operasional yaitu:

\section{Produktivitas Kerja Karyawan}

Produktivitas Kerja Karyawan adalah kemampuan yang dimiliki karyawan UD Kembang Batu Lestari dalam memanfaatkan sarana dan prasarana yang telah disediakan oleh perusahaan sehingga dapat menghasilkan output yang optimal. Produktivitas kerja karyawan diukur dari persepsi responden terhadap kuantitas kerja, kualitas kerja dan ketepatan waktu.

Insentif

Insentif, adalah pemberian balas jasa diluar gaji sebagai pengakuan perusahaan terhadap prestasi kerja dan kontribusi karyawan UD Kembang Batu Lestari, diukur dari persepsi responden terhadap insentif yang berupa insentif material dan non material.

\section{Program Jaminan Sosial}

Suatu perlindungan bagi karyawan UD Kembang Batu Lestari dalam bentuk santunan berupa uang sebagai pengganti sebagian dari penghasilan yang hilang atau berkurang dan pelayanan sebagai akibat peristiwa atau keadaan yang dialami oleh karyawan, diukur dari persepsi responden terhadap perlindungan memenuhi kebutuhan minimal karyawan beserta keluarganya, perlindungan kepastian penerimaan penghasilan yang hilang, menciptakan ketenangan bekerja

\section{Metode Pengumpulan Data}

Pengumpulan data dalam penelitian ini dilakukan dengan cara:

Kuesioner

Kuesioner adalah metode pengumpulan data yang dilakukan dengan cara memberi seperangkat pertanyaan atau pernyataan tertulis kepada responden untuk dijawab (Sugiyono, 2017).

\section{Studi Pustaka}

Studi Pustaka merupakan metode pengumpulan data atau informasi dengan membaca literaturliteratur yang dapat menunjang penelitian melalui buku-buku, jurnal atau penelitian terdahulu. Peneliti melakukan studi pustaka untuk mempelajari dan mengambil data terkait dengan penelitian ini sehingga dapat memberikan informasi tambahan dalam penelitian ini.

Internet

Internet digunakan dalam penelitian ini untuk memperoleh informasi atau data yang tidak didapatkan pada studi kepustakaan seperti jurnal online

Teknik Analisis Data 
Analisis Kuantitatif

Analisis kuantitatif digunakan untuk menganalisis data yang bersifat bilangan atau angkaangka. Dalam penelitian ini, sumber data yang digunakan adalah penarikan data primer pada variabel insentif, jaminan sosial dan produktivitas kerja, dengan menggunakan kuesioner. Data dikuantitatifkan dengan memberi skor pada masing-masing jawaban responden. Skala Likert digunakan untuk mengukur sikap, pendapat, dan persepsi seseorang atau kelompok orang tentang fenomena sosial. Setiap jawaban kuesioner mempunyai bobot atau skor (Sugiyono, 2017).

Analisis Regresi Linear Berganda

Analisis regresi linear berganda merupakan alat statistik yang digunakan untuk mengetahui pengaruh dari beberapa variabel independen (bebas) terhadap satu variabel dependen (terikat) (Siregar, 2014).

\section{Uji Asumsi Klasik}

Untuk dapat menggunakan analisis regresi linier berganda harus memenuhi asumsi klasik sebagai berikut : Uji Normalitas, Uji Multikolonieritas, Uji Heteroskedastisitas (Ghozali, 2013).

Uji F atau F-test

Uji $\mathrm{F}$ atau uji simultan digunakan untuk mengetahui apakah variabel independen atau bebas (X) secara simultan atau bersama-sama berpengaruh signifikan terhadap variabel dependen atau terikat (Y) (Prayitno, 2010).

\section{Uji t atau $t$-test}

Pengujian hipotesis dilakukan dengan uji t yang disebut juga sebagai uji signifikan individual. Uji ini menunjukkan seberapa jauh pengaruh variabel independen secara individual terhadap variabel dependen.

\section{HASIL DAN PEMBAHASAN}

Setelah data dianalisis maka dilakukan pembahasan dari hasil analisis data untuk mengetahui makna yang lebih luas dari hasil analisis yaitu :

Penyebaran kuesioner diberikan kepada 35 orang karyawan pada UD Kembang Batu Lestari di Mengwi Badung. Setelah kuesioner terisi lengkap maka dilanjutkan dengan pentabulasian kuisioner. Hasil kuesioner tersebut dilakukan pengujian instrumen berupa uji validitas dan uji reliabilitas yang hasilnya adalah berupa instrumen yang digunakan dalam penelitian ini, jika valid dan reliabel maka dilanjutkan keanalisis berikutnya.

Berdasarkan hasil uji asumsi klasik maka diketahui distribusi data pada persamaan regresi adalah normal, model regresi yang terbentuk tidak terjadi gejala multikolinearitas, kemudian untuk uji heteroskedastisitas hasil yang didapat tidak terjadi heteroskedastisitas sehingga model regresi ini bisa digunakan karena memiliki hasil prediksi yang baik atau dapat memberikan manfaat dengan baik dan jelas. Selanjutnya pengujian normalitas, hasil yang didapat adalah terlihat bahwa titik-titik menyebar disekitar garis diagonal, serta penyebarannya mengikuti arah garis diagonal sehingga dapat disimpulkan bahwa model regresi ini layak dipakai karena memiliki asumsi normalitas. Atau data berdistribusi normal dapat dlihat dari tabel Kolmogorov-Smirnov dengan hasil diketahui bahwa nilai Asymp. Sig. (2-tailed) lebih besar dari 0,05 yaitu 0,986 maka dapat diartikan seluruh data berdistribusi normal.

Persamaan regresi yang terbentuk berdasarkan hasil analisis berganda adalah $\mathrm{Y}=0,603+$ 0,400X1 + 0,515X2 menjelaskan bahwa a (Nilai konstanta), b1(Koefisien insentif X1), dan b2 (Koefisien jaminan sosial X2) diperoleh persamaan garis linier berganda antara insentif dan jaminan sosial terhadap produktivitas kerja karyawan. Dengan demikian, dapat dinyatakan bahwa tinggi rendahnya produktivitas kerja karyawan dipengaruhi secara bersama-sama oleh insentif (X1) jaminan sosial (X2).

Pengujian F-test adalah uji signifikansi koefisien regresi linier berganda diperoleh F-hitung $83,262>$ F-tabel 3,23, menunjukkan memang benar ada pengaruh signifikan secara simultan antara insentif dan jaminan terhadap produktivitas kerja karyawan dan bukan diperoleh secara kebetulan.

Uji signifikansi dengan menggunakan t-test diperoleh nilai t-hitung untuk variabel insentif dan 
jaminan sosial masing-masing sebesar 2,747 dan 4,157 > t-tabel 1,684, menunjukkan memang benar ada pengaruh yang positif dan signifikan secara parsial antara insentif dan jaminan sosial terhadap produktivitas kerja karyawan dan bukan diperoleh secara kebetulan.

Hasil ini menjelaskan bahwa insentif dan jaminan sosial, baik secara parsial maupun simultan mempunyai hubungan yang searah dan signifikan terhadap produktivitas kerja karyawan, artinya apabila insentif dan jaminan sosial semakin meningkat, baik secara parsial maupun secara simultan maka akan diikuti oleh peningkatan yang signifikan pada produktivitas kerja karyawan.

\section{SIMPULAN}

Implementasi pemberian insentif dan program jaminan sosial berpengaruh secara simultan terhadap produktivitas kerja karyawan pada UD Kembang Batu Lestari di Mengwi Badung, hal ini terbukti dari hasil uji F. Jadi hipotesis yang menyatakan implementasi pemberian insentif dan program jaminan sosial berpengaruh positip dan signifikan terhadap produktivitas kerja karyawan terbukti kebenarannya.

Implementasi pemberian insentif dan program jaminan sosial berpengaruh secara parsial terhadap produktivitas kerja karyawan pada UD Kembang Batu Lestari di Mengwi Badung, hal ini terbukti dari hasil uji t. Jadi hipotesis yang menyatakan implementasi pemberian insentif dan program jaminan sosial berpengaruh positip dan signifikan terhadap produktivitas kerja karyawan terbukti kebenarannya

Implementasi pemberian insentif pada UD Kembang Batu Lestari secara keseluruhan termasuk kategori baik, namun untuk lebih efektifnya penerapan program ini dalam meningkatkan produktivitas kerja hendaknya perlu dikaji ulang.

Implementasi program jaminan sosial pada UD Kembang Batu Lestari secara keseluruhan termasuk kategori baik, namun untuk menciptakan optimisme kenyamanan karyawan terkait kesehatan, keselamatan dan hari tuanya, hendaknya seluruh karyawan diikut sertakan dalam program BPJS/JKN sehingga karyawan semakin produktif, dan produktivatas kerja karyawan menjadi lebih baik.

Produktivitas karyawan UD Kembang Batu Lestari di Mengwi Badung dalam kategori baik, namun pihak perusahaan hendaknya tetap mempertahankan, dan lebih ditingkatkan lagi dengan membuat kebijakan yang mengacu pada UU RI NO. 24 TAHUN 2011 Tentang Badan Penyelenggara Jaminan Sosial .

\section{DAFTAR PUSTAKA}

Afrida. (2003), Ekonomi Sumber Daya Manusia. Jakarta: Ghalia Indonesia.

Badri, M . S. (2007). Manajemen Administrasi Perkantoran Modern. Jakarta: Erlangga

Ghozali, I. (2013). Aplikasi AnalisisMultivariate dengan Program SPSS.Edisi Ketujuh. Semarang: Badan PenerbitUniversitas Diponegoro.

Gorda, I. G. N. (2004). Manajemen Sumber Daya Manusia. Edisi Revisi. Denpasar: Astabrata Bali bekerjasama dengan STIE Satya Dharma. Singaraja.

Hariandja. (2011). Manajemen Sumber Daya Manusia. Jakarta: Gramedia Widiasarana

Jamsostek ( Kemnaker), UU No 40 Tahun 2004 tentang SJSN

Kansil, (2007). Ilmu Negara Umum dan Indonesia,. PT. Pradnya Paramita, Jakarta. Kelsen

Kebijakan Perlindungan Jaminan Sosial@2020

Khafidoh, S. (2015). Pengaruh Insentif danJaminan Sosial Terhadap ProduktivitasKerja Karyawan Kantor pada PT. Reakaltim Plantations di Samarinda. eJournal Ilmu AdministrasiBisnis. 3 (3): 587-599. Retrieved from https://www.portal.fisip-unmul.ac.id/site/?p=3172

Kim, H. B., \& Kim, S., \& Kim, T. T. (2017). The selection and causal effects of work incentives on labor productivity:Evidence from a two-stage roandomized controlled trail in Malawi. IZA Discussion 
Papers. Retrieved from https://www.iza.org/publications/dp/10644/the-selection-and-causal-effectsof-work-incentives-on-labor-productivity-evidence-from-a-two-stage-randomized-controlled-trial-in -malawi

Lukitasari, L. (2015). Pengaruh pelaksanaan program kesejahteraan jaminan sosial, insentif dan pelatihan kerja terhadap produktivitas karyawan CV. Ijo Geneng Ngawi. The FIPA (Forum Ilmiah Pendidikan Akuntansi). 3(1), Retrieved from http://prosiding.unipma.ac.id/index.php/FIPA/article/view/230

Martoyo, S. (2007). Manajemen Sumber Daya Manusia, Edisi 5, Cetakan Pertama. Yogyakarta: BPFE

Panggabean, S., \& Mutiara. (2002). Manajemen Sumber Daya Manusia. Bogor:Ghalia Indonesia.

Peraturan Pemerintah No. 70 Tahun (2015) tentang Jaminan Kecelakaan Kerja Dan Jaminan Kematian Bagi Pegawai Aparatur Sipil Negara [JDIH BPK RI]

Prayitno, D. (2010). Mandiri Belajar SPSS. Yogyakarta: Mediakom

Priansa, D. J. (2018). Perencanaan \& Pengembangan SDM. Bandung. Alfabeta

Sarwoto. (2010). Dasar-Dasar Organisasi Dan Manajemen. Cetakan Keenambelas. Jakarta: Ghalia Indonesia

Simamora, H. (2006). Sumber Daya Manusia. Yogyakarta: Bagian Penerbitan STIE YKPN

Siregar, K. H. (2020) Pengaruh Insentif Dan Jaminan Sosial Terhadap Produktivitas Karyawan Pada PT. Bank Muamalat Indonesia Tbk. JURNAL VISI EKONOMI AKUNTANSI DAN MANAJEMEN. 2(2), Retrieved from http://www.ibmi-medan.com/ojs/ojsibmi/index.php/JIBMI/article/view/74

Siregar, S.( 2014). Statistik Parametrik Untuk Penelitian Kuantitatif. Jakarta: Bumi Aksara.

Subagyo, B. (2017). Pengaruh Pemberian Insentif Terhadap Produktivitas Kerja Karyawan Pada Rumah Sakit Aisyah Blitar. Ampindo Blitar. Retrieved from http://arthavidya.wisnuwardhana.ac.id/index.php/ arthavidya/article/download/60/45

Sudiro, A. (2011). Perencanaan Sumber Daya Manusia. Malang: UB Press

Supriadi, Y. N. (2017). Social Security Contribution to Productivity and Wages in Labour Organization Perspective. IOP ebooks. IOP Conference Series: Materials Science and Engineering, 180(1). https:// ui.adsabs.harvard.edu/abs/2017MS\%26E..180a2020S/abstract

Sutrisno, E. (2009). Manajemen Sumber Daya Manusia. Jakarta: Kencana

Sugiyono, (2017). Metode Penelitian Kuantitatif, Kualitatif dan R\&D, Bandung: CV Alfabeta.

Undang-Undang No. 3 pasal 1 ayat 1 Tahun 1992 tentang jaminan sosial tenaga kerja.

Wibowo. (2011). Manajemen Kinerja. Edisi Ketiga. Jakarta: PT Raja Grafindo Persada. 